\title{
ANALISIS PENINGKATAN KINERJA SISWA DALAM KERAPIHAN MENJAHIT KERAH JAS BERBASIS METODE DEMONSTRASI DAN EKSPERIMEN
}

\author{
Etin Suryatin \\ SMK Negeri 9 Bandung \\ J1. Soekarno Hatta Km.10 Buah Batu Bandung 40286 \\ Email : etinsuryatin@yahoo.com
}

\begin{abstract}
Abstrak : Penelitian ini bertujuan untuk menemukan cara-cara yang efektif mengajar melalui penggunaan paduan metode demonstrasi dan eksperimen. Metoda yang digunakan adalah Penelitian Tindakan Kelas (PTK) dengan prosedur penelitian terbagi dalam 2 siklus. Tiap siklus diawali dengan perencanaan,tindakan, observasi dan refleksi. Instrumen yang digunakan dalam penelitian ini ini terdiri dari 3 jenis yaitu pedoman observasi guru, angket respon peserta didik dan hasil pekerjaan peserta didik. . Analisis data diolah secara deskriptif mengacu pada proses dan hasil kerja siswa.Hasil Penelitian menunjukkan bahwa penggunaan paduan metoda demonstrasi dan eksperimen dapat meningkatkan kerapihan peserta didik dalam menjahit kerah jas, penggunaan paduan metoda demonstrasi dan eksperimen dapat meningkatkan aktifitas peserta didik dalam mengikuti pembelajaran menjahit kerah jas, dan penggunaan paduan metode demonstrasi dan eksperimen ektif digunakan oleh instruktur sebagai salah satu strategi pembelajaran dalam memberikan materi menjahit dengan mesin khususnya menjahit kerah jas.
\end{abstract}

Kata Kunci : metode demonstrasi, metode eksperimen, penelitian tindakan kelas.

\begin{abstract}
This study aims to find effective ways to teach using the demonstration and experimentation. The method used was action research with the research procedure is divided into two cycles.Each cycle begins with planning, action, observation and reflection. The instrument used in this study consists of three types of teacher observation, questionnaire responses of students and the work of the students.Analysis of the data processed by descriptive refers to the process and results of student work. The results showed that the use of demonstration and experimental methods can improve psychomotor skills, the use of blend and experimental demonstration method can increase the activity of students, and the use of demonstrations and experiments can be used by instructors as a teaching strategy.
\end{abstract}

Keyword : demontration method, experiment method, classroom action research

\section{PENDAHULUAN}

Pendidikan Menengah Kejuruan, merupakan salah satu lembaga pendidikan formal yang memiliki peran menyiapkan peserta didik agar siap bekerja, baik bekerja secara mandiri (wiraswasta) maupun mengisi lowongan pekerjaan yang 
tersedia. Oleh karena itu Sekolah Menengah Kejuruan dituntut untuk mampu menghasilkan lulusan sebagaimana yang diharapkan dunia kerja yaitu hadirnya sumber daya manusia yang memiliki kompetensi sesuai dengan bidang pekerjaannya. Atas dasar itu, maka kurikulum sekolah kejuruan harus dirancang dan disesuaikan dengan kondisi kebutuhan dunia kerja.

SMKN 9 Bandung merupakan salah satu sekolah kejuruan Pariwisata dengan berbagai program keahlian, diantaranya program keahlian Tata Busana dengan mempunyai berbagai tujuan, yaitu membekali peserta didik dengan pengetahuan, keterampilan dan sikap agar kompeten dalam hal: (1) Mengukur,membuat pola , menjahit dan menyelesaikan busana, (2) Memilih bahan tekstil dan bahan pembantu secara tepat, (3) Menggambar macam-macam busana sesuai kesempatan, (4)Menghias busana sesuai desain, dan (5) Mengelola usaha di bidang busana (Depdiknas, Kurikulum SMK 2004)

Untuk mencapai tujuan tersebut, maka disusun standar kompetensi program keahlian dengan berbagai kompetensi, diantaranya Menjahit dengan Mesin yang harus dikuasai peserta didik pada semester 3 dengan karakteristik pembelajaran $30 \%$ teori dan $70 \%$ praktek.

Kompeten tidaknya peserta didik terhadap hasil belajarnya, sangat tergantung pada kemampuan peserta didik dalam mengikuti seluruh proses pembelajaran. Dalam pembelajaran menjahit dengan mesin, peserta didik secara garis besarnya dituntut untuk memahami dan memiliki keterampilan mulai dari mempersiapkan tempat kerja dan alat kerja (alat jahit pokok dan alat bantu jahit) menyiapkan mesin jahit, mengoperasikan mesin jahit serta menjahit bagian-bagian busana, dalam hal ini menjahit bagian kerah jas yang diharapkan dari menjahit bagian-bagian busana tersebut, harus memenuhi kriteria atau sesuai dengan standar kompetensi yang harus dimiliki peserta didik yaitu produk yang dihasilkan haruslah rapi, bersih dengan menggunakan teknik jahit yang benar, dapat menyelesaikan pekerjaan tepat pada waktunya serta memperhatikan kesehatan dan keselamatan kerja (ergonomic) sehingga terhindardari kecelakaan seperti tertusuk jarum,tersetrum. Dengan demikian peserta didik dapat bekerja dengan konsentrasi dan menyenangkan. 
Berdasarkan hasil temuan sebagai studi penelitian awal pada semester 1 kelas $\mathrm{X}$ Busana 2, menunjukkan bahwa hasil belajar peserta didik dalam membuat jas (blazer) khususnya pada bagian kerah relatif belum memuaskan ,sehingga tingkat ketuntasan belajar beberapa orang peserta didik tertunda atau belum sesuai dengan Standar Ketuntasan Minimal (SKM) yang ditentukan yaitu $(7,0)$. Melihat kondisi ini, maka perlu upaya dengan melakukan tindakan mengamati dan merefleksikan pembelajaran yang difokuskan terhadap peningkatan peserta didik dengan mencoba memadukan antara metoda demontrasi dan eksperimen, dengan harapan peserta didik selain dapat mempraktekkan pembuatan kerah jas, juga bersama sama dengan instruktur mencoba mempraktekkan cara pembuatan kerah jas dengan teknik yang lain serta mengamati proses dan hasil percobaan tersebut untuk membuktikan teknik mana yang lebih mudah pengerjaannya serta hasil yang lebih rapi, dengan harapan pemahaman dan keterampilan peserta didik dalam pembuatan kerah jas lebih terampil melekat dalam ingatannya sehingga pembelajaran lebih menyenangkan.

Penelitian ini diharapkan dapat menemukan cara-cara yang efektif dalam menerapkan metoda pembelajaran untuk memfasilitasi proses dan hasil belajar yang optimal, sehingga tujuan yang ingin dicapai dalam penelitian ini adalah :

1. Meningkatkan kerapihan menjahit kerah jas pada peserta didik kelas XI Busana 3 SMKN 9 Bandung dalam mata diklat menjahit dengan mesin setelah menggunakan metoda demonstrasi dan eksperimen.

2. Meningkatkan aktifitas peserta didik kelas XI Busana 3 SMKN 9 Bandung dalam mengikuti pembelajaran menjahit kerah jas mata diklat menjahit dengan mesin setelah menggunakan metoda demonstrasi dan eksperimen.

3. Mengetahui efektifitas penggunaan metoda demonstrasi dan eksperimen dalam pembelajaran menjahit kerah jas pada mata diklat menjahit dengan mesin di kelas XI Busana 3 SMKN 9 Bandung.

\section{METODE}

Metoda yang digunakan adalah Penelitian Tindakan Kelas (PTK). Dilakukan dengan seting yang terfokus pada kegiatan yang terjadi didalam kelas atau 
proses belajar mengajar yang terjadi di kelas, bukan pada input kelas (Materi, silabus, dll) ataupun Output (Hasil belajar). PTK Harus tertuju pada aktifitas yang terjadi di dalam kelas.(Suharjono, 2006; Fransisca, 2006;).

Desain penelitian yang dipakai adalah The action research spiral (based on (Kemmis and MC Taggart dalam Hopkins 1988: 14) Program-program tindakan diurutkan sebagai berikut:

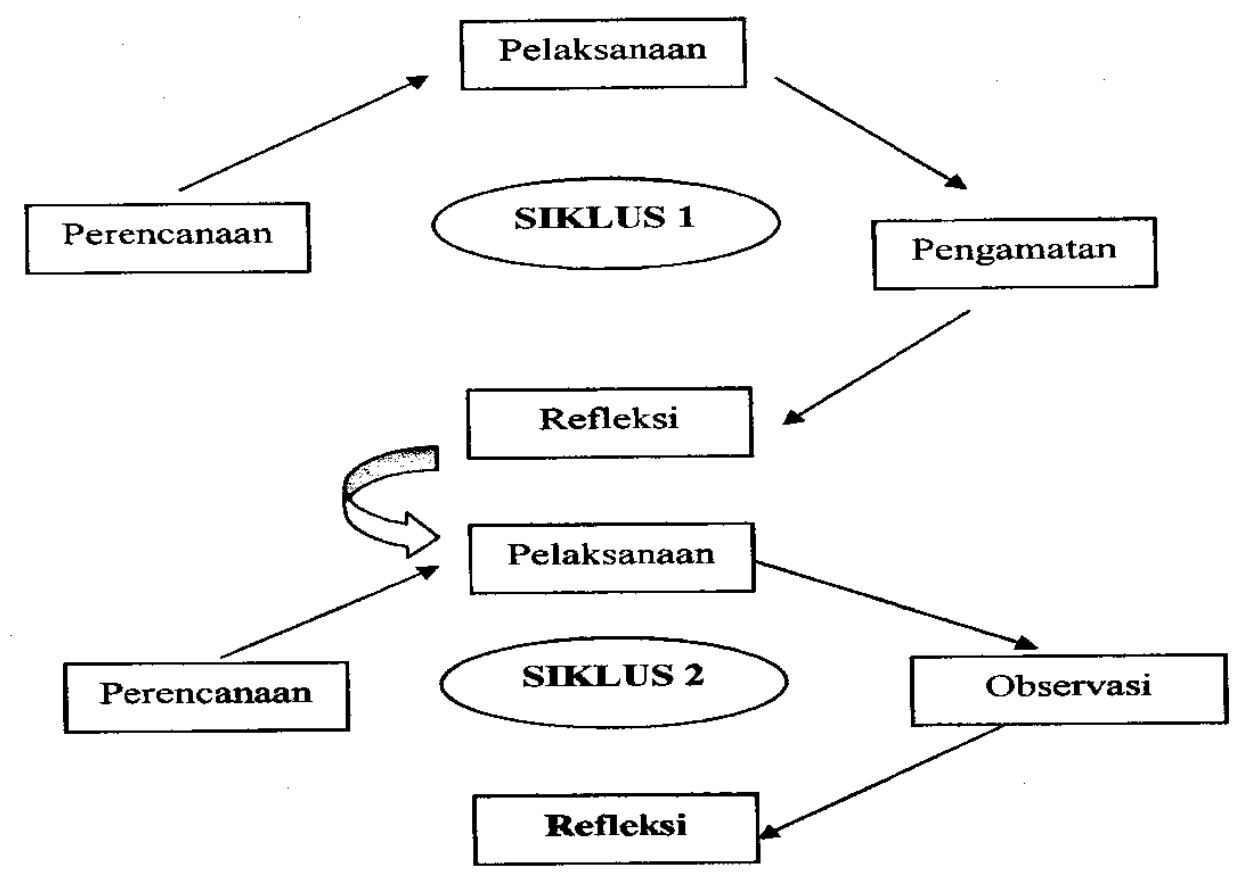

Gambar 1. Prosedur PTK

Dari alur tahapan pelaksanaan penelitian di atas, dapat dijelaskan bahwa penelitian dimulai dari PERENCANAAN - TINDAKAN - OBSERVASI REFLEKS1 (Yaitu merenungkan, memikirkan, dan menilai) - PERENCANAAN (atau perencanaan kembali atau perbaikan rencana) - TINDAKAN OBSERVASI - REFLEKS1 ... Dan seterusnya hingga mencapai tujuan akhir atau memperoleh hasil yang memuaskan.

Prosedur penelitian terbagi dalam 2 siklus dengan masing-masing tahapannya mengacu pada desain PTK Kemmis \& McTaggart. Penelitian diawali 
dengan menetapkan masalah penelitian melalui pra penelitian, merencanakan pembelajaran dan dilanjutkan dengan pelaksanaan tindakan. Tiap siklus diawali dengan perencanaan,tindakan, observasi dan refleksi.

Instrumen yang digunakan dalam penelitian ini ini terdiri dari 3 jenis yaitu pedoman observasi guru, angket respon peserta didik dan hasil pekerjaan peserta didik dalam menjahit kerah jas.

Subyek dalam penelitian ini adalah peserta didik kelas XI Busana 3 SMKN 9 Bandung yang berjumlah 29 orang., sedangkan waktu penelitian akan dilaksanakan sekitar pertengahan Agustus sampai dengan September 2009.

Analisis data dalam penelitian ini adalah dengan menggunakan metode deskripsi dengan melihat proses dan hasil kerja peserta didik dalam hal menjahit kerah jas yang dilakukan 2 kali penilaian yaitu menjahit kerah jas dengan teknik jahit 1 dan teknik jahit 2. Penilaian yang dilakukan disesuaikan dengan standar kompetensi peserta didik,berdasarkan skor yang ditentukan instruktur

Pedoman skor hasil belajar dan aspek yang dinilai adalah sebagai berikut :

1. Menyiapkan tempat dan peralatan kerja

2. Mengoperasikan mesin jahit

3. Teknik jahit

4. Kerapihan

5. Kebersihan

6. Ketepatan waktu

Tabel 1.

Kriteria Hasil Belajar Peserta Didik

\begin{tabular}{|c|c|}
\hline Kriteria Hasil Belajar & Interpretasi \\
\hline $00,00-69,99$ & Belum Kompeten \\
\hline $70,00-74,99$ & Cukup kompeten \\
\hline $75,00-84,94$ & Kompeten \\
\hline $85,00-90,00$ & Sangat kompeten \\
\hline
\end{tabular}

\section{HASIL PENELITIAN}

Pada siklus I, terutama pada awal pembelajaran, aktifitas peserta didik dirasakan kurang ada perhatian mereka masih beranggapan kalau menjahit kerah jas 
itu susah, hal ini terbukti dari hasil angket respon peserta didik yang menunjukkan hampir seluruhnya $(82,76 \%)$ peserta didik menjawab setuju pada pernyataan mendapat kesulitan dalam menjahit kerah jas. Setelah instruktur menjelaskan dan mendemonstrasikan dengan rinci langkah-langkah menjahit kerah jas dengan teknik jahit I sesuai job sheet yang tersedia, peserta didik mengikuti langkah perlangkah cara menjahit kerah jas tersebut disertai juga bimbingan instruktur, terlihat adanya perubahan aktifitas peserta didik, mereka terlihat senang, bersemangat dalam menjahit, hal ini terbukti dari hasil angket yang menunjukkan hampir setengahnya (41,38\%) peserta didik menjawab sangat setuju dan sebagian besar lagi (58, 62 \%) menjawab setuju merasa senang mendapat materi pembelajaran menjahit kerah jas dengan metoda demonstrasi, karena langkah kerja lebih jelas. Selain itu pun peserta didik terlihat bersemangat mengerjakannya, hal ini terbukti juga dari hasil angket yang menunjukkan seluruhnya (100\%) mereka menjawab setuju dari pernyataan bersemangat mengikuti pembelajaran menjahit kerah jas dengan metoda demosntrasi yang diperagakan secara rinci.

Setelah peserta didik mengikuti pembelajaran selama dua kali pertemuan yaitu 10 jam pembelajaran, diperoleh nilai peserta didik sebagian besar (58,62 \%) dinyatakan kompeten, sebagian kecil $(24,14 \%)$ cukup kompeten dan sebagian kecil lagi $(17,24 \%)$ belum kompeten. Dari hasil tersebut dapat disimpulkan masih perlu adanya usaha baik dari instruktur maupun peserta didik untuk meningkatkan hasil/prestasi yang dicapai sampai peserta didik mencapai nilai dengan criteria minimal cukup kompeten dengan kisaran nilai 70,00 s.d. 74, 99.

Hasil pembelajaran pada siklus II yaitu menjahit kerah jas dengan teknik jahit 2 dengan strategi pembelajaran menggunakan kolaborasi metoda demonstrasi dan eksperimen menunjukkan adanya peningkatan. Peserta didik terlihat lebih senang, bersemangat mengikuti pembelajaran, terlebih setelah diberi kesempatan untuk mencoba menjahit kerah jas dengan teknik jahit 2 dan membandingkannya dengan teknik jahit 1, sehingga peserta didik bisa menemukan sendiri teknik jahit yang lebih muda dan hasilnya lebih rapih. Hal ini terbukti dari pendapat/tanggapan peserta didik tentang menjahit kerah jas dengan teknik jahit 2 dengan kolaborasi metoda 
demonstrasi dan eksperimen membuat belajar lebih senang, sebagian besar (69\%) menyatakan setuju, bahkan ada juga yaitu hampir setengahnya $(27,6 \%)$ menyatakan sangat setuju dan hanya seorang saja yang menyatakan kurang setuju. Selain itu sebagian besar $(65,52 \%)$ peserta didik menyatakan sangat setuju menjahit kerah jas dengan teknik jahit 2 lebih mudah dan hasilnya lebih parah, dan hampir setengahnya lagi $(34,48 \%)$ menyatakan setuju. Temuan lain setelah peserta didik menemukan teknik jahit yang dirasakan lebih mudah dan hasilnya lebih rapih, terungkap sebaian besar $(58,62 \%)$ menyatakan setuju dan hampir setengahnya $(37,93 \%)$ menyatakan sangat setuju mereka termotivasi untuk sering menjahit busana yang berkerah jas.

Dari serangkaian proses pembelajaran siklus II yang telah dilakukan, akhirnya diperoleh hasil peserta didik dalam hal mejahit kerah jas yaitu 18 orang dari 29 orang jumlah peserta didik atau sebagian besar $(62,06 \%)$ peserta didik dinyatakan kompeten dengan nilai berkisar 75 s.d 84,99. 7 orang yaitu $(24,14 \%)$ dinyatakan sangat kompeten dengan nilai berkisar antara 85 s.d 90 dan hanya 4 orang saja $(13,80$ $\%$ ) yang dinyatakan cukup kompeten yaitu mendapat nilai 70 s.d 74,99. Dengan demikian seluruh peserta didik dalam menjahit kerah jas dapat dikatakan berhasil karena passing grade nilai produktif yang sudah disepakati yaitu 70 .

\section{PEMBAHASAN}

Dengan adanya perubahan aktifitas belajar peserta didik dalam menjahit kerah jas menjadi catatan khusus bagi peneliti/instruktur bahwa metoda demonstrasi yang menuntut aktifitas dari kedua belah pihak efektif digunakan dalam mengajarkan materi pembelajaran yang bersifat praktek khususnya praktek menjahit pakaian. Selain itu dengan demonstrasi yang disertai langkah-langkah kerja yang terperinci memotivasi peserta diklat untuk menyelesaikan pekerjaan tepat waktunya, hal ini terlihat dari hasil pengamatan instruktur baha peserta didik dengan sungguh-sungguh dalam memanfaatkan waktu untuk menjahit kerah jas serta tanggapan seluruh (100\%) peserta didikpun menyatakan setuju dengan metoda demonstrasi yang disertai peragaan yang rinci mereka merasa senang, sehingga dapat memacu untuk dapat 
menyelesaikan pekerjaan tepat waktu. Walaupun dalam kenyataannya belum seluruh peserta didik dapat menyelesaikan pekerjaan tepat pada waktunya.

Temuan lain dari hasil observasi instruktur dan angket tanggapan peserta didik diperoleh data masih banyak yaitu sebagian besar $(65,52 \%)$ dan peserta didik yang menyatakan kurang setuju dan hanya sebagian kecil saja (20,7 \%) yang menyatakan setuju kalau dengan metoda demonstrasi dapat menghapus anggapan sulitnya menjahit kerah jas. Setelah adanya demonstrasi dan penjelasan secara rinci dan berulang-ulang dari instruktur tentang cara menjahit kerah jas dengan teknik jahit I, terlihat peserta didik merasa senang menjahit kerah jas. Hal ini sejalan juga dengan hasil angket yang menyatakan hampi seluruh $(96,35 \%)$ peserta didik menyatakan senang menjahit kerah jas dengan teknik jahit I.

Dengan demikian kolaborasi metoda demonstrasi dan eksperimen dapat menghapus anggapan sulitnya menjahit kerah jas. Hal ini terbukti dari sebagian besar $(51,27 \%)$ peserta didik menyatakan sangat setuju dan hampir setengahnya $(41,4 \%)$ menyatakan setuju bahwa dengan kolaborasi metode demonstrasi dan eksperimen dalam hal menjahit kerah jas dapat menghapus anggapan sulitnya menjahit kerah jas seperti anggapan semula pada awal pembelajaran pada siklus I. Hal lain terungkap sebagian besar $(51,72 \%)$ dan hampir setengahnya $(48,27 \%)$ menyatakan mersas senang dan berusaha membuat karya yang lebih baik lagi setelah mereka belajar menjahit kerah jas dengan menggunakan kolaborasi metoda demonstrasi dan eksperimen. Pendapat lain sebagian besar yaitu masing-masing $(48,27 \%)$ pesera didik menyatakan setuju dan sangat setuju belajar menjahit kerah jas dengan kolaborasi metoda demonstrasi dan eksperimen tidak membosankan.

\section{KESIMPULAN}

Berdasarkan hasil pembahasan pada pelaksanaan pembelajaran menjahit kerah jas siklus I dan II dengan menggunakan paduan metoda demonstrasi dan eksperimen pada kelas XI Busana 3 SMKN 9 Bandung, dapat disimpulkan sebagai berikut: 
1. Penggunaan paduan metoda demonstrasi dan eksperimen dapat meningkatkan kerapihan peserta didik dalam menjahit kerah jas terutama pada siklus ke II setelah peserta didik menemukan sendiri teknik menjahit kerah jas yang dianggap lebih mudah dan hasilnya lebih rapih.

2. Penggunaan paduan metoda demonstrasi dan eksperimen dapat meningkatkan aktifitas peserta didik dalam mengikuti pembelajaran menjahit kerah jas. Hal ini terbukti dari aktifitas peserta didik selama proses pembelajran terutama pada siklus II, mereka melakukan uji coba untuk membandingkan cara menjahit kerah jas dengan teknik jahit 1 dan 2 sampai akhirnya peserta didik menemukan teknik jahit 2 yang mereka anggap lebih mudah dan hasilnya lebih rapih.

3. Berdasarkan hasil pembahasan angket dan nilai prestasi yang dicapai peserta didik setelah mengikuti proses pembelajaran yang menunjukkan meningkatnya aktifitas dan kerapihan peserta didik dalam menjahit kerah jas, sehingga seluruh peserta didik dapat mencapai nilai dengan kriteria mulai dari cukup kompeten sampai sangat kompeten, membuktikan bahwa penggunaan paduan metoda demonstrasi dan eksperimen, efektif digunakan oleh instruktur sebagai salah satu strategi pembelajaran dalam memberikan materi menjahit dengan mesin khusunya menjahit kerah jas.

\section{DAFTAR PUSTAKA}

Abu Ahmadi (2005). Strategi Belajar Mengajar. Bandung : Pustaka Setia.

Arifah A. Riyanto (2003). Teori Busana. Bandung: Yapendo.

Depdiknas (2004). Kurikulum SMK. Jakarta : Depdiknas

Eri Novida (1999). Pembuatan Blazer. Jakarta: Departemen Pendidikan Nasional, Direktorat Pendidikan Menengah Kejuruan.

Fransiska Sudarga (2006. Pedoman Penyusunan Proposal. Bandung: Lembaga Penelitian UPI 
Hopkins D. (1998). A Teachers Guide To Classroom Research. Buckingham: Open University press.

J.J Hasibuan (2008). Prosese Belajar Mengajar. Bandung: Rosda Karya

Saiful Bahri Jamarah (2005).Guru Dan Anak Didik Dalam Interaksi Edukatif. Jakarta: Rineka Cipta.

Suharjono (2006). PTK Sebagai Kegiatan Pengembangan Profesi Guru. Bandung: Bumi Aksara. 